\title{
LA-UR-20-27563
}

Approved for public release; distribution is unlimited.

Title: $\quad$ Los Alamos National Laboratory Meteorology Monitoring Program: 2019

Data Completeness/Quality Report

Author(s): $\quad$ Bruggeman, David Alan

Stanton, Gregory T.

Waight, Kenneth Thomas III

White, Ian Michael

Coronado, Melissa A.

Intended for: Report

Issued: 2020-09-25 
Disclaimer:

Los Alamos National Laboratory, an affirmative action/equal opportunity employer, is operated by Triad National Security, LLC for the National Nuclear Security Administration of U.S. Department of Energy under contract 89233218CNA000001. By approving this article, the publisher recognizes that the U.S. Government retains nonexclusive, royalty-free license to publish or reproduce the published form of this contribution, or to allow others to do so, for U.S. Government purposes. Los Alamos National Laboratory requests that the publisher identify this article as work performed under the auspices of the U.S. Department of Energy. Los Alamos National Laboratory strongly supports academic freedom and a researcher's right to publish; as an institution, however, the Laboratory does not endorse the viewpoint of a publication or guarantee its technical correctness. 


\section{Los Alamos National Laboratory Meteorology Monitoring Program: 2019 Data Completeness/ Quality Report}




\section{Authors: David Bruggeman, Greg Stanton, Kenneth Waight, lan White, and Melissa Coronado (EPC-CP)}

Los Alamos National Laboratory, an affirmative action/equal opportunity employer, is operated by Triad National Security, LLC, for the National Nuclear Security Administration of the U.S. Department of Energy under contract 89233218CNA000001. By acceptance of this article, the publisher recognizes that the U.S. Government retains a nonexclusive, royalty-free license to publish or reproduce the published form of this contribution, or to allow others to do so, for U.S. Government purposes. Los Alamos National Laboratory requests that the publisher identify this article as work performed under the auspices of the U.S. Department of Energy. Los Alamos National Laboratory strongly supports academic freedom and a researcher's right to publish; as an institution, however, the Laboratory does not endorse the viewpoint of a publication or guarantee its technical correctness. 


\section{CONTENTS}

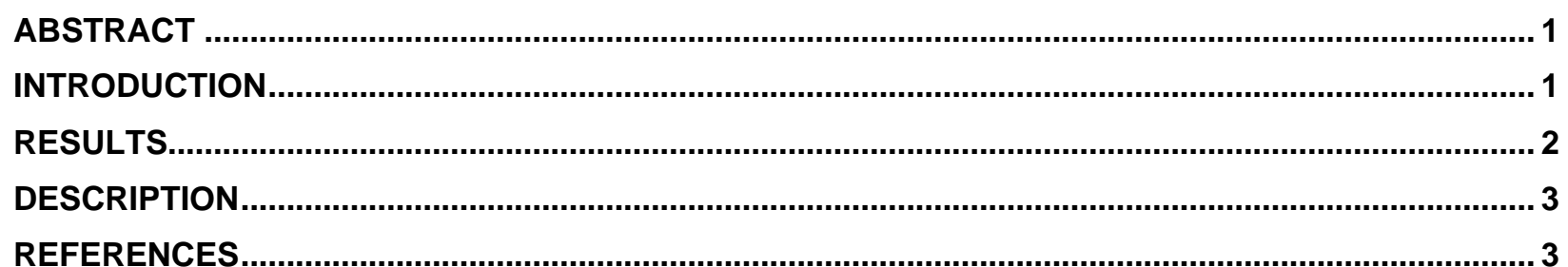




\begin{abstract}
This report summarizes data completeness by tower and by instrument for 2019 and compares that data with the Los Alamos National Laboratory (LANL) and the ANSI/ANS-3.11-2015 standard. This report is designed to make data users aware of data completeness and any data quality issues. LANL meteorology monitoring goals include $95 \%$ completeness for all measurements. The ANS 2015 standard requires $90 \%$ completeness for all measurements. This report documents instrument/tower issues as they impact data completeness.
\end{abstract}

\title{
INTRODUCTION
}

LANL operates four mesa-top meteorology towers: Technical Area (TA) 06, TA-49, TA-53, and TA-54. An additional tower is located in Mortandad Canyon (TA-5 MDCN), and a rain gauge at North Community (NCOM).

A description of the meteorology monitoring network is found in Dewart and Boggs (2014). Mesa-top towers are instrumented at 1.2 meters $(\mathrm{m}), 11.5 \mathrm{~m}, 23 \mathrm{~m}$, and $46 \mathrm{~m}$. In addition, TA06 is instrumented at $92 \mathrm{~m}$. The TA-5 MDCN tower is $10 \mathrm{~m}$ in height and is instrumented at 1.2 $\mathrm{m}$ and $10 \mathrm{~m}$. Data are collected every 15 minutes. Range checking is done on each measurement every 15 minutes; data that are beyond normal ranges are eliminated from the data set and replaced by a code for missing data. In addition, data are reviewed weekly by meteorologists to identify bad data not identified by range checking. The data steward eliminates these data from the data set and replaces them with a code for missing data. The instrument technicians also review that data and schedule instrument replacement as required. Data completeness is determined by the number of total 15-minute records available versus the total number of possible measurements for the entire year. As a rule, the meteorologists do not attempt to estimate data that are eliminated as bad data. Original datalogger records, containing bad data, can be recalled from program archival storage.

The majority of missing data occur for short periods of time as a result of:

- towers down for instrument swap out/calibration,

- tower hoist inspections,

- power failures/network communication issues,

- wind propellers freezing in snowstorms,

- temperature probe aspiration fan failure, and

- battery failure for solar/terrestrial radiation instruments

Only other primary instrumentation failures will be documented in this report. 


\section{RESULTS}

Summary of 2019 data completeness for all stations to meet $90 \%$ annual completeness

\begin{tabular}{|c|c|c|c|c|c|c|c|}
\hline Sensor & Level* & TA-06 & TA-49 & TA-53 & TA-54 & TA-05 & NCOM \\
\hline \multirow{4}{*}{ Wind Speed } & 1 & $99.83 \%$ & $99.89 \%$ & $99.92 \%$ & $99.77 \%$ & $99.29 \%$ & \\
\hline & 2 & $99.83 \%$ & $99.93 \%$ & $99.91 \%$ & $99.86 \%$ & & \\
\hline & 3 & $99.83 \%$ & $99.93 \%$ & $99.91 \%$ & $99.88 \%$ & & \\
\hline & 4 & $99.83 \%$ & & & & & \\
\hline \multirow{4}{*}{ Wind Direction } & 1 & $99.83 \%$ & $99.89 \%$ & $95.86 \%$ & $99.77 \%$ & $99.29 \%$ & \\
\hline & 2 & $99.83 \%$ & $96.49 \%$ & $99.89 \%$ & $99.86 \%$ & & \\
\hline & 3 & $99.83 \%$ & $99.93 \%$ & $99.92 \%$ & $99.88 \%$ & & \\
\hline & 4 & $99.83 \%$ & & & & & \\
\hline \multirow{4}{*}{ Vertical Speed } & 1 & $98.77 \%$ & $99.10 \%$ & $99.22 \%$ & $98.97 \%$ & $99.39 \%$ & \\
\hline & 2 & $98.68 \%$ & $99.10 \%$ & $98.75 \%$ & $98.97 \%$ & & \\
\hline & 3 & $98.68 \%$ & $99.11 \%$ & $99.33 \%$ & $98.91 \%$ & & \\
\hline & 4 & $98.65 \%$ & & & & & \\
\hline \multirow{5}{*}{ Temperature } & 0 & $99.97 \%$ & $99.95 \%$ & $99.97 \%$ & $99.97 \%$ & $99.69 \%$ & \\
\hline & 1 & $99.83 \%$ & $99.90 \%$ & $99.92 \%$ & $99.88 \%$ & $99.35 \%$ & \\
\hline & 2 & $99.83 \%$ & $99.90 \%$ & $99.92 \%$ & $99.88 \%$ & & \\
\hline & 3 & $98.46 \%$ & $99.90 \%$ & $99.42 \%$ & $99.88 \%$ & & \\
\hline & 4 & $99.83 \%$ & & & & & \\
\hline Pressure & 0 & $99.97 \%$ & & & $97.98 \%$ & & \\
\hline Relative Humidity & 0 & $99.77 \%$ & $99.74 \%$ & $99.92 \%$ & $99.98 \%$ & & \\
\hline Dew point & 0 & $99.76 \%$ & $99.95 \%$ & $99.91 \%$ & $99.97 \%$ & & \\
\hline Precipitation & 0 & $99.99 \%$ & $99.99 \%$ & $99.98 \%$ & $99.98 \%$ & & $99.96 \%$ \\
\hline Snow depth & 0 & $99.54 \%$ & & & & & \\
\hline Shortwave $\downarrow$ & 0 & $99.97 \%$ & $99.93 \%$ & $99.98 \%$ & $99.98 \%$ & $99.68 \%$ & \\
\hline Shortwave $\uparrow$ & 0 & $99.97 \%$ & & & $99.98 \%$ & & \\
\hline Longwave $\downarrow$ & 0 & $99.97 \%$ & & & $99.98 \%$ & & \\
\hline Longwave $\uparrow$ & 0 & $99.97 \%$ & & & $99.98 \%$ & & \\
\hline Net Radiation & 0 & $99.97 \%$ & & & $99.96 \%$ & & \\
\hline \multicolumn{2}{|c|}{ Maximum } & $99.99 \%$ & $99.99 \%$ & $99.98 \%$ & $99.98 \%$ & $99.69 \%$ & $99.96 \%$ \\
\hline \multicolumn{2}{|c|}{ Minimum } & $98.46 \%$ & $96.49 \%$ & $95.86 \%$ & $97.98 \%$ & $99.29 \%$ & $99.96 \%$ \\
\hline
\end{tabular}

*Levels correspond to height. Level 0 at $1.2 \mathrm{~m}, 1$ at $11.5 \mathrm{~m}, 2$ at $23 \mathrm{~m}, 3$ at $46 \mathrm{~m}$, and 4 at $92 \mathrm{~m}$.

$=$ met $90 \%$ data completeness

$=$ did not meet $90 \%$ data completeness

$=$ sensor not located at that station 


\section{DESCRIPTION}

All stations (i.e., TA-06, TA-49, TA-53, TA-54, TA-05 MDCN, and NCOM) instruments exceeded the $90 \%$ data completeness in 2019.

Based on the June 2020 calibration tests, wind directions at TA-49 and TA-53 failed calibration that resulted in the lowest completeness at approximately $96 \%$. The wind direction at TA-49 level 2 failed at 330 degrees by 7 degrees. The wind direction at TA-53 level 1 failed calibration at 30 degrees by 6.1 degrees. Thus, the wind directions from these failed directions were eliminated from the October 2019 to June 2020 data set.

\section{REFERENCES}

ANSI/ANS 3.11-2015, Determining Meteorological Information for Nuclear Facilities, American Nuclear Society, 2015.

Dewart, J. and M. Boggs 2014: "Meteorological Monitoring at Los Alamos," Los Alamos National Laboratory report LA-UR-14-23378. 